\title{
BMJ Open Associations of state-level and county- level hate crimes with individual-level cardiovascular risk factors in a prospective cohort study of middle-aged Americans: the National Longitudinal Survey of Youths 1979
}

Krisztina Gero (D) , ${ }^{1}$ Farzad Noubary, ${ }^{1}$ Ichiro Kawachi, ${ }^{2}$ Christopher F Baum (D) , ${ }^{3}$ Robert B Wallace, ${ }^{4}$ Becky A Briesacher, ${ }^{5}$ Daniel Kim ${ }^{1,6}$

To cite: Gero K, Noubary F, Kawachi I, et al. Associations of state-level and county-level hate crimes with individual-level cardiovascular risk factors in a prospective cohort study of middle-aged Americans: the National Longitudinal Survey of Youths 1979. BMJ Open 2022;12:e054360. doi:10.1136/ bmjopen-2021-054360

- Prepublication history for this paper is available online. To view these files, please visit the journal online (http://dx.doi. org/10.1136/bmjopen-2021 054360).

Received 09 June 2021 Accepted 23 December 2021

Check for updates

(C) Author(s) (or their employer(s)) 2022. Re-use permitted under CC BY-NC. No commercial re-use. See rights and permissions. Published by BMJ.

For numbered affiliations see end of article.

Correspondence to

Dr Krisztina Gero;

k.gero@northeastern.edu

\section{ABSTRACT}

Background There have been long-standing debates about the potential health consequences of hate crimes over and above other types of crimes. Besides the direct consequences for victims, less is known about whether hate crimes have spillover effects onto the health of local residents.

Methods We drew data on cardiovascular disease risk factors from middle-aged Americans in the National Longitudinal Survey of Youths 1979 and on hate crimes from the FBl's Uniform Crime Reports. Employing multivariable logistic regression, we estimated the associations between changes in state/county-level all and group-specific hate crime rates from 2000 to 2006 and incident individual-level diabetes, hypertension, obesity and depressive symptoms from 2008 to 2016. All models controlled for individual-level sociodemographic factors and financial strain, county-level and state-level changes in the total crime rate, the percentage of nonHispanic Black and Hispanic/Latino residents, and median household income, as well as state-level changes in the percentage of residents aged 65 years or older and the unemployment rate.

Results 1-SD increases in state-level all and race/ ethnicity-based hate crime rates were associated with $20 \%$ (OR 1.20, 95\% Cl 1.05 to 1.35) and 15\% higher odds (OR 1.15, 95\% Cl 1.01 to 1.31) of incident diabetes, respectively. At the county level, a 1-SD increase in the all hate crime rate was linked to $8 \%$ higher odds (OR 1.08, $95 \% \mathrm{Cl} 1.00$ to 1.16 ) of obesity, while a 1-SD increase in the race/ethnicity-based hate crime rate was associated with $8 \%$ higher odds (OR $1.08,95 \% \mathrm{Cl} 1.01$ to 1.15) of obesity and $9 \%$ higher odds (OR 1.09, 95\% $\mathrm{Cl} 1.02$ to 1.17) of hypertension. We found no significant associations for depressive symptoms, and no interactions between race/ethnicity-based hate crime rates and individual-level race/ethnicity.

Conclusion Living in areas with higher hate crime rates may confer higher odds of hypertension, diabetes and obesity.
Strengths and limitations of this study

- To our knowledge, this is the first study that explores the impacts of hate crimes and its specific bias motivations as an area-level social determinant on individual-level health.

- We explored our main associations at both the state and county levels, and investigated the possibility of differential effects across subpopulations based on individual race/ethnicity and sex.

- Using a nationally-representative sample of middleaged Americans, all models were adjusted for the county-level and state-level total crime rates, as well as a variety of key potential confounders at the state, county and individual levels.

- Racial/ethnic minorities as opposed to Whites might be less likely to report to authorities both racial and non-racial hate crimes, which could impede the correct estimation of race/ethnicity-specific associations.

- Measuring neighbourhood hate crime rates at a lower aggregation level (eg, Census tracts as a proxy for neighbourhoods) might be more appropriate to estimate its effects on individuals' health.

\section{INTRODUCTION}

A hate crime is defined as a "criminal offence against a person or property motivated in whole or in part by an offender's prejudice against a race, religion, disability, sexual orientation, ethnicity, gender or gender identity. ${ }^{1}$ Apart from actual membership, these crimes can extend to victims who are perceived to be a part of a targeted group. ${ }^{2}$ Compared with offences with other motivations, hate crimes are reported to be more likely to result in severe injury and hospitalisation, to cause short-term and long-term emotional and psychological distress, and to 
involve multiple offenders and serial/repeated attacks. ${ }^{3-5}$ Hate crimes may also lead to reduced trust and greater fear as well as group separation, affecting both the actual victims and the community to which they belong. ${ }^{6}$ The substantial rise in hate crimes over the past 2 years have further brought the issue of hate crimes to the forefront of public discourse. ${ }^{78}$

There have been long-standing debates in the literature about the potential health consequences of hate crimes over and above other types of crimes. Apart from direct mental and physical health effects for victims, hate crimes are often seen as sending threatening messages to the groups to which the victims are perceived to belong. ${ }^{239-11}$ However, little is known about whether hate crimes may have spillover effects onto the health of residents in areas with high rates of such crimes. According to a parallel strand of research, widely publicised incidents of police brutality against Black Americans have been suggested to increase the levels of mental distress and depression among Black residents living in the same areas. ${ }^{12} 13$ Evoking feelings of injustice and anger, hate crimes are more likely to provoke retaliatory crimes and instigate community unrest as well. ${ }^{3591114}$ Attacking the core of societal values, bias-motivated crimes can also offend the collective moral code, leading to the outrage of the general community as a whole. ${ }^{39}$

Whether community-level exposures to hate crimes are linked to increases in other health indicators, such as cardiovascular disease (CVD) risk factors, is not yet established.

Living in a high-crime neighbourhood might lead to chronic stress whereby the fight-or-flight response is triggered frequently, inducing a prolonged activation of the physiological stress response. ${ }^{15}$ As part of the initial stage of the stress response, epinephrine and norepinephrine are released in the body, increasing heart rate, blood pressure and blood glucose levels. ${ }^{15}$ Due to chronic exposure to neighbourhood stressors, individuals may develop heightened reactivity, while the stress response might become generalised-'seemingly detached from specific stimuli'. ${ }^{15}$ Following the initial stage, the stress response enters the resistance phase, where adrenocorticotropic stimulating hormone is released from the anterior pituitary gland leading to cortisol release from the adrenal cortex, raising blood pressure and blood glucose levels (decreased glucose metabolism, glucose production from fats and proteins), potentially leading to hyperglycaemia, central obesity and hypertension. ${ }^{15}$ Also, the hyperactivity of the hypothalamic-pituitary-adrenal axis and the subsequent cortisol increase has been consistently linked to depression and anxiety disorders. ${ }^{1516}$ In turn, anxiety and depression have been shown to increase heart rate, blood pressure and circulating cortisol, ultimately leading to atherosclerosis (artery wall hardening and thickening/ fatty plaque buildup due to excess cortisol) and heart disease. ${ }^{15}$ Furthermore, psychological stress responses in the form of fear and anxiety may lead to adverse coping behaviours (eg, excess drinking, smoking), fear of exercising outdoors and sleep disruption, and have been proposed to link community exposures such as violence and crime to CVD risks including depression, obesity and increased blood pressure and blood glucose levels. ${ }^{15}$ 17-21 However, whereas hate crimes have been posited to evoke strong feelings of anger and stress both in the victims and the community when compared with non-hate crimes, ${ }^{3}$ 9-11 14 studies have yet to explore the potential spillover health hazards posed by bias motivation, that is, specific types of hate crimes, such as race/ethnicity-based, sexual orientation-based or religion-based hate crimes. ${ }^{22}$

To address this existing gap in the literature, we used a nationally-representative sample of middle-aged Americans to examine the associations between state-level and county-level hate crime rates and the incidence of four individual-level CVD risk factors: hypertension, diabetes, obesity and depressive symptoms. Based on prior work reporting that proximity to crime incidents has a significant negative impact on individuals' perceptions and fear of violence, we posited that county-level hate crime rates might show more consistent associations with individuallevel CVD risk factors than state-level rates. ${ }^{23-25}$

\section{METHODS}

\section{Study population}

Data were obtained on a nationally-representative sample of middle-aged adults from the US National Longitudinal Survey of Youths 1979 (NLSY79). The NLSY79 was launched in 1979, interviewing 12686 respondents between the ages of 15 and 22 years, and has collected information on sociodemographic factors, health, as well as areas of residence through 26 waves of follow-up surveys between 1980 and 2016. Information on chronic conditions was first collected in the 2008 wave. The presence of depressive symptoms was first assessed when respondents turned 40 years old between 1998 and 2004. Among respondents who participated in both the baseline and final follow-up waves $(n=6593)$, those with missing data on the health outcomes $(0.1 \%-2.8 \%)$, as well as those with a pre-existing health condition at baseline (depending on the modelled health outcome to maximise the available sample size: $22.5 \%$ for hypertension, $8.2 \%$ for diabetes, $34.4 \%$ for obesity and $14.2 \%$ for depressive symptoms), were excluded from the current analyses.

\section{Patient and public involvement}

Patients and members of the public were not involved in the design, conduct, reporting or dissemination of this research.

\section{Outcome variables}

The study outcomes were self-reported measures of obesity, diabetes, hypertension, and depressive symptoms. Incident hypertension and diabetes cases were identified in 2016, based on respondents' answers to the following questions: (1) 'Are you currently taking any medication to control your blood pressure?' and (2) 'Are you currently 
taking any medication to control your blood sugar level?'. Incident obesity cases were defined as a body mass index $(\mathrm{BMI}) \geq 30 \mathrm{~kg} / \mathrm{m}^{2}$ in 2016 among those respondents with $\mathrm{BMI}<30 \mathrm{~kg} / \mathrm{m}^{2}$ in 2008 based on self-reported height and weight measures.

The presence of depressive symptoms was assessed based on the 7-item Centre for Epidemiologic Studies Depression Scale Short Form (CES-D-SF), an abbreviated version of the 20-item CES-D. The CES-D-SF asks about respondents' feelings and behaviour during the preceding week-included in surveys between 1998 and 2004, once participants reached the age of 40 , as well as between 2008 and 2014, once participants turned 50 years old. We used a CES-D-SF cut-off score of 8+ (vs 0-7) to identify those with high depressive symptomatology, that has been previously shown to exhibit moderately acceptable validity and internal consistency reliability and perform as well as or better than the CES-D. ${ }^{26}$ New cases with high depressive symptoms were identified between 2008 and 2014 among respondents who had a score $\leq 7$ at age 40 .

\section{Exposure variables}

We abstracted hate crime data based on the Uniform Crime Reports (UCR) of the Federal Bureau of Investigation (FBI) from the open Inter-university Consortium for Political and Social Research repositories. ${ }^{27}{ }^{28}$ We considered hate crimes based on sexual orientation, religion, disability and race/ethnicity (anti-Black, anti-Hispanic/ Latino and anti-White prejudice). The explored geographical levels included US states (average area: $196667 \mathrm{~km}^{2}$; smallest: $4001 \mathrm{~km}^{2}$-Rhode Island; largest: 1723337 $\mathrm{km}^{2}$-Alaska/average population: 6.4 million; smallest: 0.6 million-Wyoming; largest: 39.5 million-California) and counties (average area: $3129 \mathrm{~km}^{2}$; smallest: 31 $\mathrm{km}^{2}$-Kalawao County, Hawaii; largest: $51947 \mathrm{~km}^{2}$-San Bernardino County, California/average population: 104.4 thousand; smallest: 86-Kalawao County, Hawaii; largest: 10039.1 thousand-Los Angeles County, California). Each 1-SD change in the state-level and county-level bias specific hate crime rates per 100000 population was calculated as the difference between the first and last years of a lagged exposure period for each outcome. The exposure periods were set between 2000 and 2006 for hypertension, diabetes and obesity; and between 1991 and 1996 for depressive symptoms. Since prejudice against persons with disabilities was included in the Violent Crime Control and Law Enforcement Act in 1994, and the FBI started gathering data on this bias motivation in 1997, estimates for disability-based hate crime rates were not available for 1991-1996. ${ }^{27}$ Hate crimes based on antirace/ethnicity sentiments other than anti-Black, anti-Hispanic/Latino and anti-White prejudice were not assessed separately, since in the NLSY79 questionnaire, race/ethnicity only included three response categories: 'Hispanic', 'Black' or 'non-Black/non-Hispanic'. Antigender/gender-identityrelated hate crimes were not reported in the years and counties included in the current analyses.

\section{Covariates}

Our statistical models included both individual-level and area-level variables to control for potential confounding. For example, income is a known CVD risk factor that can also influence participants' choice of area of residence, and thereby the levels of hate crimes to which they were exposed..$^{29}$ Likewise, median household income might affect crime rates in the neighbourhood as well as shape individual CVD risks. ${ }^{30}$

Individual-level covariates consisted of age (continuous), sex (female, male), race/ethnicity (non-Hispanic Black, non-Hispanic White or Hispanic/Latino), education ( $\leq 6$ th grade, $7-9$ th grade, $10-12$ th grade, $1-4$ years of college, $\geq 5$ years of college), marital status (married, separated, divorced, widowed, never married), individual income (US\$0, US\$1-US\$28 000, US\$28 100US $\$ 57900, \geq$ US $\$ 58000$ /year), and work hours per week. Factors representing financial strain were also adjusted for including health insurance coverage, a missed bill payment in the past 5 years, bankruptcy and residence type. Data on individual-level factors were obtained from the 2002 and 2008 waves of the NLSY79 for models evaluating depressive symptoms and hypertension, diabetes and obesity, respectively.

At the county level, models controlled for changes in the total crime rate, the percentage of non-Hispanic Black and Hispanic/Latino residents, and median household income. At the state level, we adjusted for changes in the total crime rate, the percentages of non-Hispanic Black and Hispanic/Latino residents and residents aged 65 years or older, as well as the unemployment rate and median household income. Information on all arealevel covariates was drawn from the Current Population Survey (CPS), the Census and the American Community Survey (ACS) by the US Census Bureau. ${ }^{31-33}$ In the ACS, the earliest available 5-year estimates were centred in 2007 (from 2005 to 2009), while Census information was provided for 2000 . We, therefore, calculated change scores for state-level, and county-level covariates as differences between the first and last years of the period between 2000 and 2007 for obesity, diabetes and hypertension. For depressive symptoms, data on area-level unemployment rates were available for all years from 1990 to 2010 in the CPS, while intercensal estimates of median household income were provided for 1995. Data on the percentages of non-Hispanic Black and Hispanic/Latino residents and residents aged 65 years or older were drawn from the 1990 and 2000 Census. Accordingly, we calculated change scores as differences between 1991 and 1996 for the unemployment rate, 1990-1995 for median household income and 1990-2000 for the percentage non-Hispanic Black, percentage Hispanic/Latino and percentage $\geq 65$ years to best match the crime rate exposure period.

\section{Statistical analysis}

Descriptive statistics were used to assess sample characteristics based on respondents included in the final analytic sample. We employed the missing indicator method to 
handle missing covariate data (missingness: $0.0 \%-3.7 \%$ ). We fit multivariable logistic regression models to estimate the associations between mutually adjusted countylevel and state-level bias specific hate crime rates and individual-level CVD risk factors. All models controlled for individual-level, county-level and state-level covariates to reduce the likelihood of residual confounding, and incorporated cluster variables (state) as well as survey weights to account for the nested structure and the probability of selection, differential response rates, non-interviews and random variation associated with sampling. Variance inflation factors were $<3$ in all models, supporting the absence of multicollinearity between model variables. ${ }^{34}$

To explore whether hate crimes were differentially associated with CVD risk factors depending on race/ ethnicity and sex, we further assessed the significance of interaction terms between the bias-specific crime rates, race/ethnicity and sex. Each set of interaction terms was tested in a separate model-including all covariates listed above-instead of testing all possible interaction terms in the same model.

We used SAS V.9.4 (SAS Institute) to perform all analyses. An $\alpha$ level of 0.05 was employed to determine statistical significance.

\section{RESULTS}

Respondent characteristics for each analytic sample are presented in table 1. Among all respondents $(\mathrm{N}=6593), 38.7 \% \quad(\mathrm{n}=2552)$ developed at least one, while $10.0 \% \quad(n=662)$ developed at least two of the examined CVD risk factors during the follow-up period (data not shown). After exclusions, the analytic sample sizes were 5351 for diabetes, 4495 for hypertension, 3605 for obesity and 5205 for depressive symptoms. We identified 1103 incident hypertension, 602 incident diabetes and 622 incident obesity cases in 2016, as well as 672 incident cases of high depressive symptoms between 2008 and 2014. The mean baseline age was 46.5-46.6 years, except for depressive symptoms (mean 40.9), where the study baseline was set 6 years earlier due to limited data availability on mental health. Approximately half of the participants were female $(51.3 \%(n=1848)-53.2 \%$ $(\mathrm{n}=2846))$, and approximately $60 \%(58.3 \% \quad(\mathrm{n}=3121)$ - $62.6 \%(\mathrm{n}=3259)$ ) were married. The respondents' mean individual income ranged from US\$36 091US $\$ 43,783$, with lower incomes reported in earlier years for depressive symptoms models, while around $50 \%(48.3 \%(\mathrm{n}=2172)-50.2 \%(\mathrm{n}=1808))$ were higher educated. Slightly more than half of the participants were White $(52.2 \% \quad(\mathrm{n}=2795)-55.5 \% \quad(\mathrm{n}=2000))$, around one-third was Black $(27.2 \% \quad(\mathrm{n}=1223)-30.4 \%$ $(\mathrm{n}=1628))$, and nearly one-fifth were Hispanic $(16.8 \%$ $(\mathrm{n}=607)-19.0 \%(\mathrm{n}=852))($ table 1$)$.

At the county level, the mean all hate crime rate change reached 1.14 per 100000 population between 1991 and 1996, while varying between -0.03 and 0.001 for the 2000-2006 period. Antirace/ethnicity sentiments accounted for the largest proportion of the reported hate crimes, with race/ethnicity-based hate crime rates at 1.2 per 100000 population in 1991, 2.1 in 1996, and 1.7-1.8 in both 2000 and 2006. The number of sexual orientation-based and religion-based hate crimes increased from 0.1 in 1991 to 0.4 per 100000 population in 2000/2006 for antisexual orientation and from 0.3 in 1991 to $0.4-0.5$ in $1996 / 2000 / 2006$ for antireligion sentiments. The corresponding crime rates per 100000 population at the state level were 1.2 in 1991, 2.2 in 1996, 1.8 in 2000, and 1.7 in 2006 for race/ethnicity-based hate crimes; and 0.1-0.4 and $0.3-0.5$ for sexual orientation-based and religionbased hate crimes, respectively. The mean change for state-level all hate crime rates was 1.3 per 100000 population between 1991 and 1996, and -0.1 between 2000 and 2006.

Table 2 shows the multivariate-adjusted ORs with $95 \%$ CIs for the associations between hate crime rates and four CVD risk factors, with key findings highlighted below.

\section{Diabetes}

At the state level, 1-SD increases in all and race/ ethnicity-based (total) hate crime rates were associated with $20 \%$ (OR 1.20; 95\% CI 1.05 to 1.35 ) and $15 \%$ (OR 1.15; 95\% CI 1.01 to 1.31) higher odds of incident diabetes, respectively. For hate crimes directed toward specific groups, state-level anti-Black hate crime rates were associated with a higher odds of diabetes (OR $1.19 ; 95 \%$ CI 1.06 to 1.34 ). Among other biases, a 1-SD increase in state-level sexual orientation-based hate crime rate was associated with a $23 \%$ higher odds of developing diabetes (OR 1.23; 95\% CI 1.09 to 1.39 ). However, in the same model, county-level higher sexual-orientation-based hate crime rate was marginally associated with a lower odds of incident diabetes (OR $0.91 ; 95 \%$ CI 0.83 to $1.00 ; \mathrm{p}=0.046$ ).

\section{Obesity}

At the county level, a 1-SD increase in all and race/ ethnicity-based (total) hate crime rates were associated with a $8 \%$ higher odds of developing obesity (OR $1.08 ; 95 \%$ CI 1.00 to $1.16 ; \mathrm{p}=0.049$ for all and OR 1.08 ; $95 \%$ CI 1.01 to 1.15 for race/ethnicity-based hate crimes). Among group-specific biases, anti-White hate crime rates were positively associated with the odds of obesity (OR $1.09 ; 95 \%$ CI 1.01 to 1.18 ) at the county level. Disability-based hate crime rates were associated with higher odds of obesity at both the state and county levels with ORs of 1.14 (95\% CI 1.06 to 1.23 ) and 1.06 (95\% CI 1.03 to 1.09 ), respectively.

\section{Hypertension}

At the county level, 1-SD increase in total race/ ethnicity-based and anti-Black hate crime rates were associated with $9 \%$ (OR 1.09; 95\% CI 1.02 to 1.17 ) and $8 \%$ (OR $1.08 ; 95 \%$ CI 1.00 to 1.16 ; $\mathrm{p}=0.041$ ) 


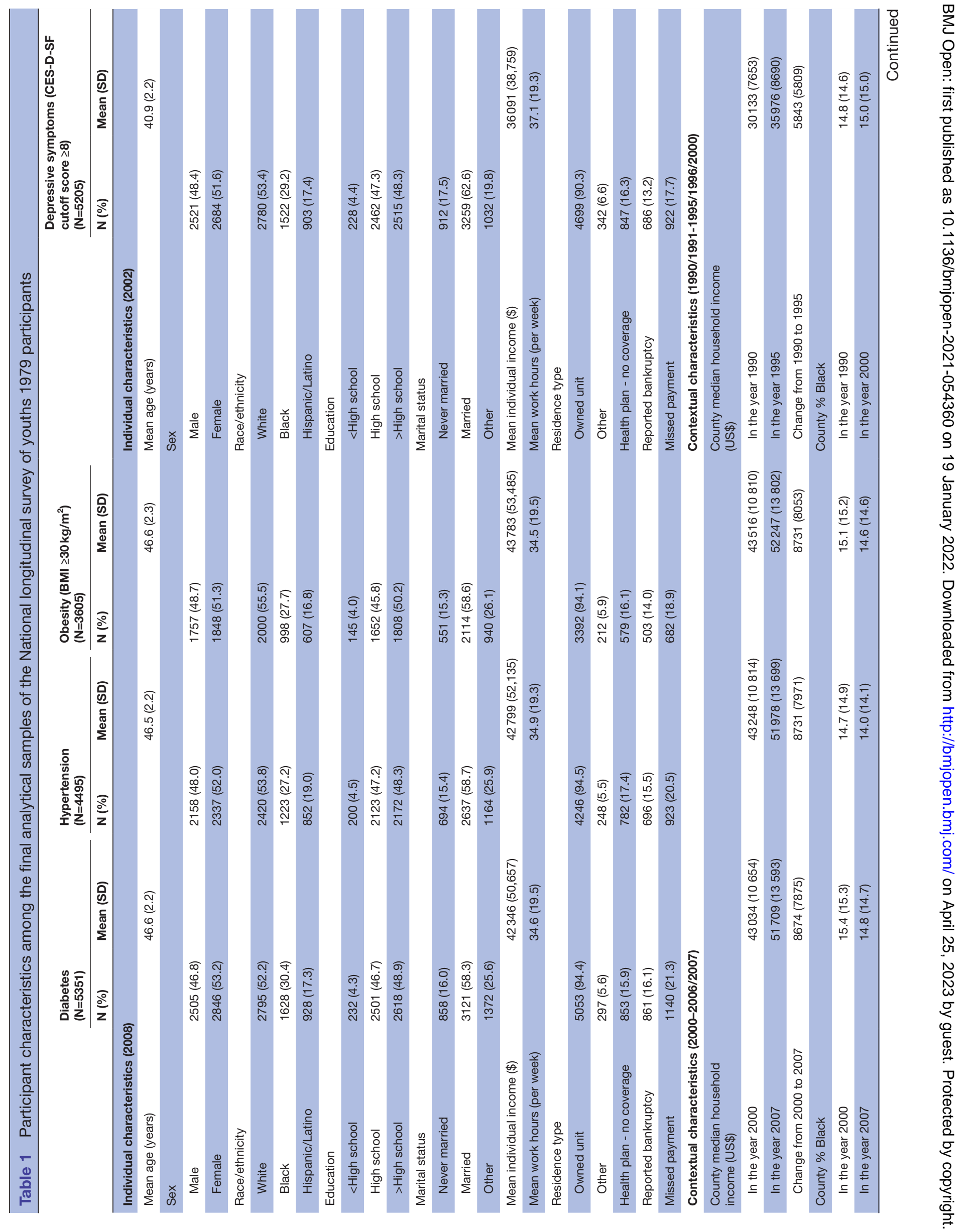




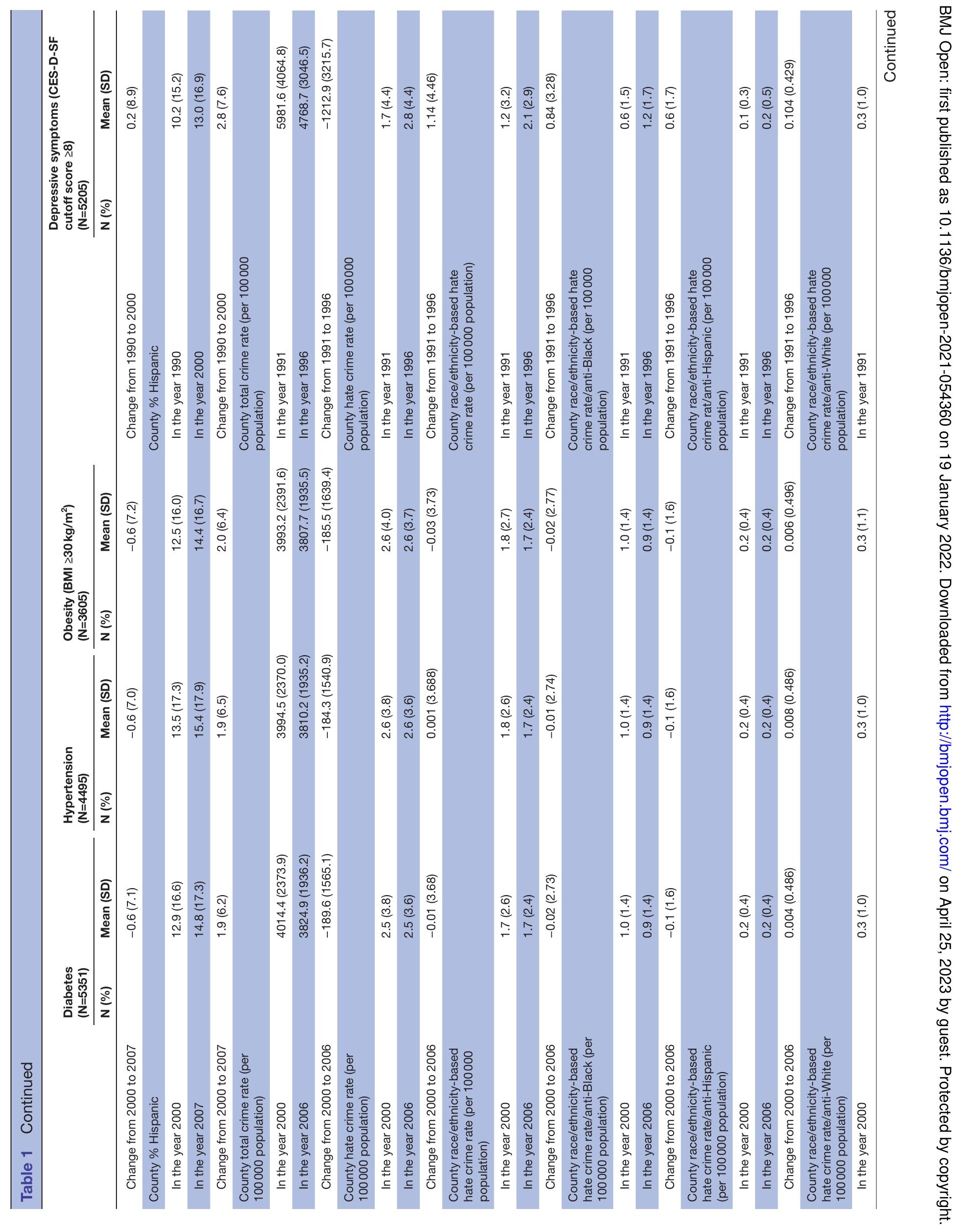




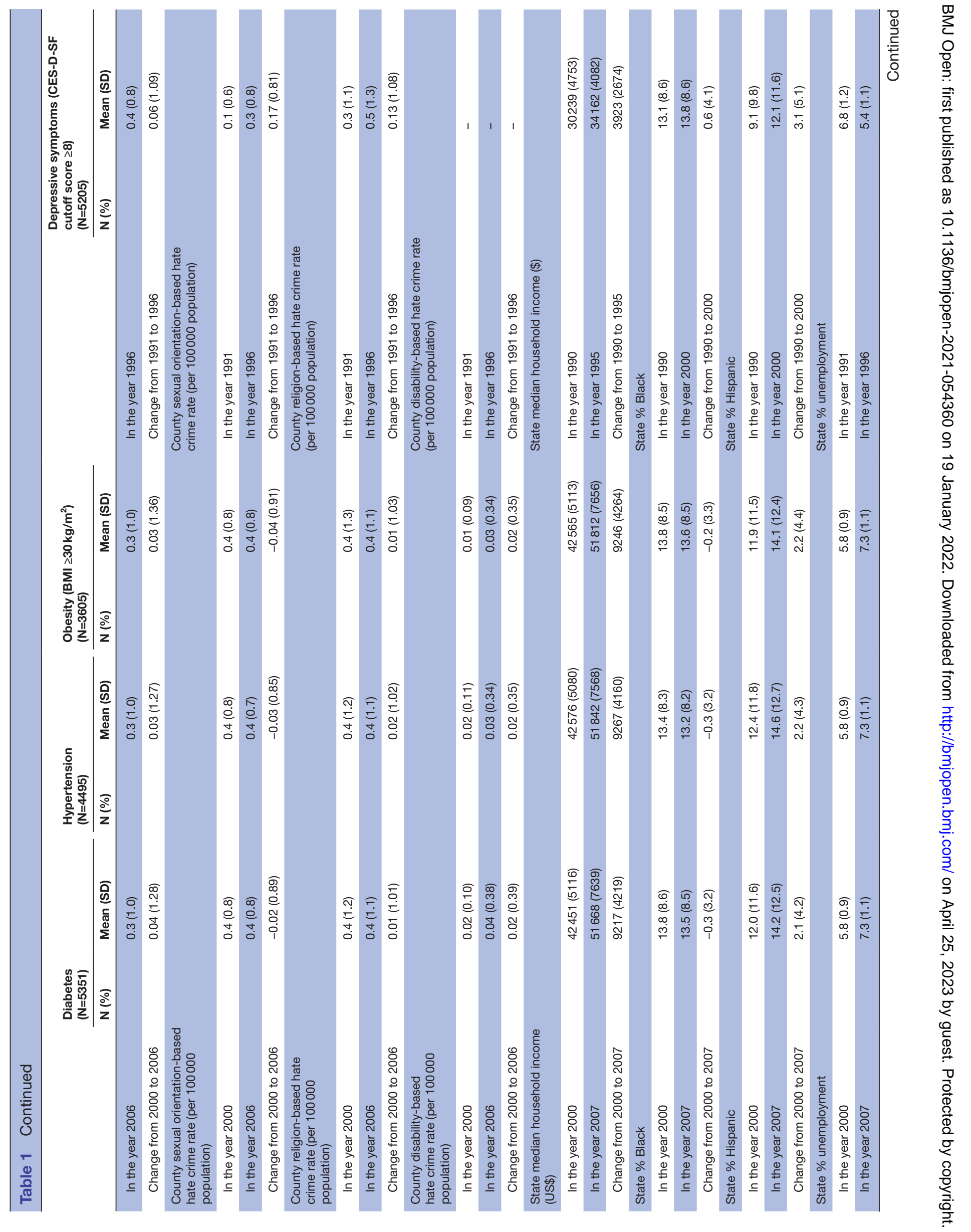




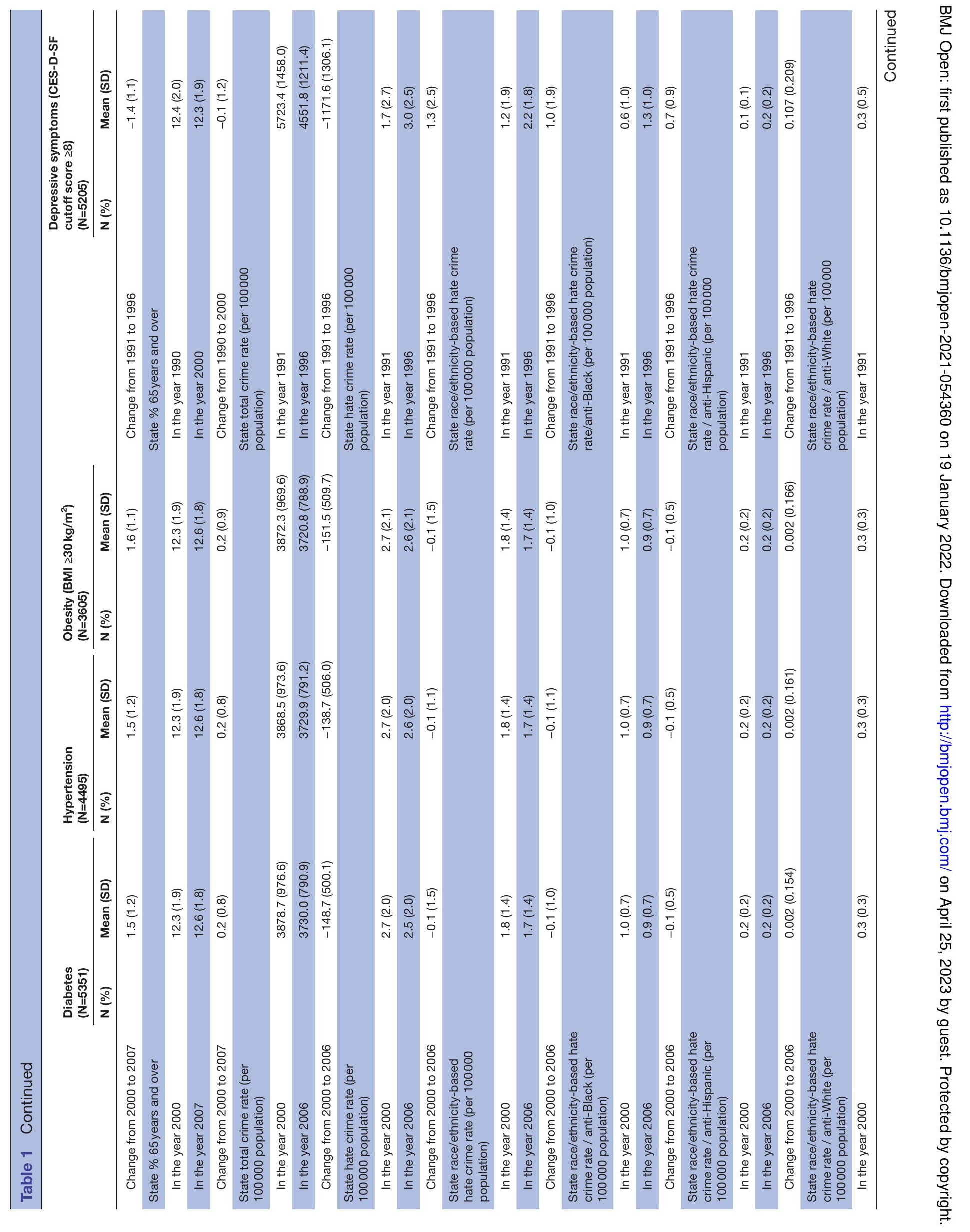




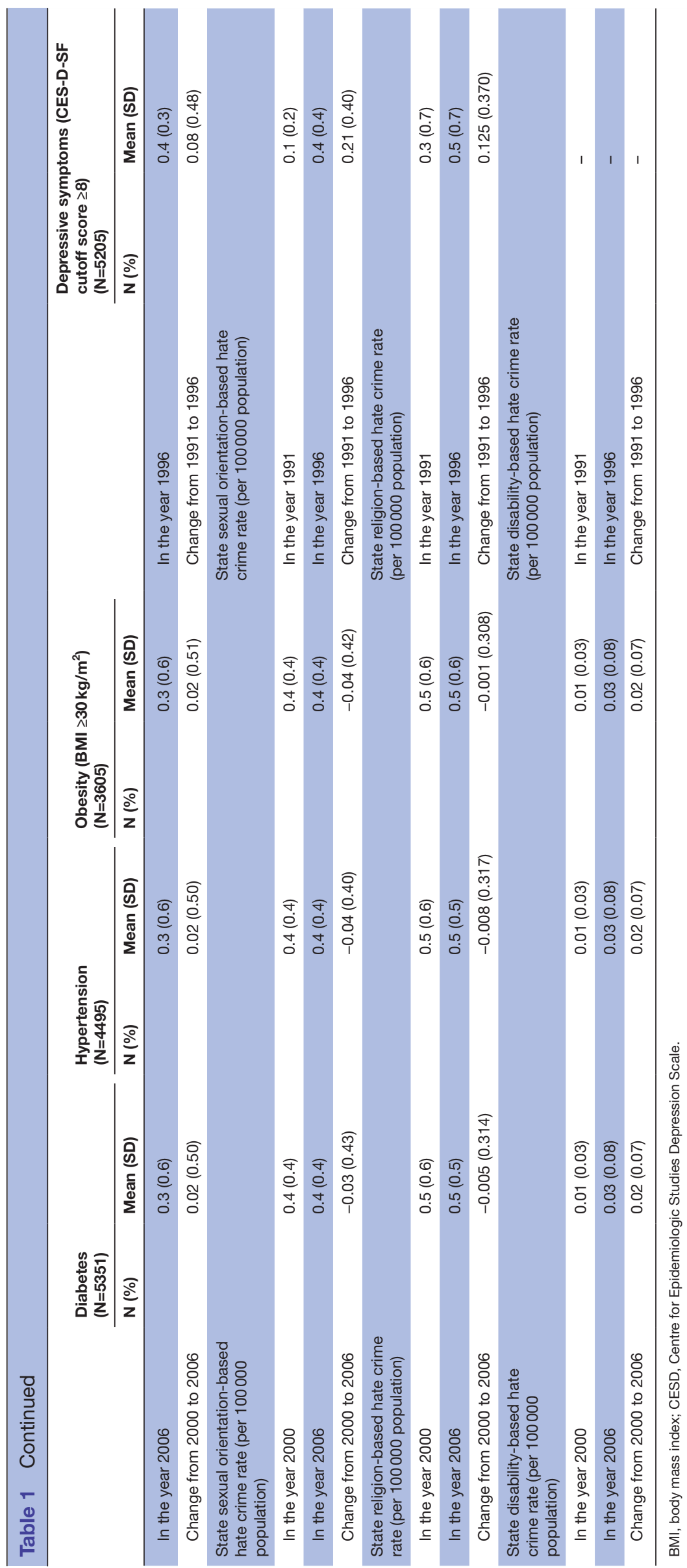

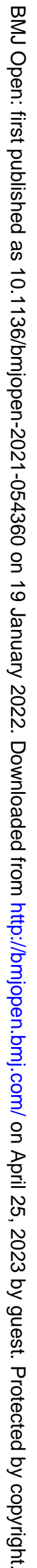


Table 2 Multivariable-adjusted odds ratios (ORs) for associations between county-level and state-level hate crime rates in the USA and individual-level CVD risk factors

\begin{tabular}{|c|c|c|c|c|}
\hline & $\begin{array}{l}\text { Diabetes } \\
\text { (N (event)=602/5351) } \\
\text { OR }(95 \% \mathrm{Cl})\end{array}$ & $\begin{array}{l}\text { Hypertension } \\
\text { (N (event)=1103/4495) } \\
\text { OR }(95 \% \mathrm{Cl})\end{array}$ & $\begin{array}{l}\text { Obesity (BMI } \geq 30 \mathrm{~kg} / \mathrm{m}^{2} \text { ) } \\
\text { (N(event) }=622 / 3605) \\
\text { OR }(95 \% \mathrm{Cl})\end{array}$ & $\begin{array}{l}\text { (CES-D-SF cutott score } \\
\geq 8) \\
\text { (N (event) }=672 / 5205) \\
\text { OR }(95 \% \mathrm{Cl})\end{array}$ \\
\hline All hate crimes & 0.95 (0.86 to 1.04$)$ & 1.06 (0.99 to 1.13$)$ & $1.08(1.00 \text { to } 1.16)^{\star}$ & 1.03 (0.91 to 1.17$)$ \\
\hline Race/ethnicity based & 0.96 (0.88 to 1.05$)$ & $1.09(1.02 \text { to } 1.17)^{*}$ & $1.08(1.01 \text { to } 1.15)^{*}$ & 1.03 (0.90 to 1.19$)$ \\
\hline Anti-Black & 1.00 (0.89 to 1.12$)$ & $1.08(1.00 \text { to } 1.16)^{*}$ & $1.02(0.95$ to 1.10$)$ & 1.03 (0.91 to 1.17$)$ \\
\hline Anti-White & 0.96 (0.89 to 1.03$)$ & $1.00(0.93$ to 1.07$)$ & $1.09(1.01 \text { to } 1.18)^{*}$ & 1.03 (0.93 to 1.13$)$ \\
\hline Sexual orientation based & $0.91(0.83 \text { to } 1.00)^{*}$ & 0.99 (0.88 to 1.12$)$ & 1.07 (0.94 to 1.21$)$ & 0.98 (0.90 to 1.07$)$ \\
\hline Religion based & 1.05 (0.93 to 1.18$)$ & $0.93(0.86$ to 1.00$) \dagger$ & 0.95 (0.85 to 1.05$)$ & 1.03 (0.94 to 1.13$)$ \\
\hline Disability based & 0.98 (0.93 to 1.04$)$ & 1.03 (0.97 to 1.08$)$ & 1.06 (1.03 to 1.09$) \ddagger$ & NA§ \\
\hline Anti-Black & 1.19 (1.06 to 1.34$)$ १ & 1.07 (0.98 to 1.18$)$ & 1.08 (0.95 to 1.24$)$ & 1.02 (0.91 to 1.14$)$ \\
\hline Anti-Hispanic & 1.05 (0.92 to 1.20$)$ & 1.04 (0.97 to 1.12$)$ & $1.02(0.88$ to 1.18$)$ & $1.04(0.93$ to 1.17$)$ \\
\hline Anti-White & 1.06 (0.92 to 1.21$)$ & 0.96 (0.89 to 1.03$)$ & 0.97 (0.82 to 1.16$)$ & 1.01 (0.90 to 1.13$)$ \\
\hline Sexual orientation based & 1.23 (1.09 to 1.39$)$ १ & 1.05 (0.94 to 1.16$)$ & 0.99 (0.86 to 1.12$)$ & 1.03 (0.93 to 1.15$)$ \\
\hline Religion based & $1.06(0.90$ to 1.24$)$ & $1.10(1.01 \text { to } 1.20)^{*}$ & 1.09 (0.93 to 1.29$)$ & 0.97 (0.86 to 1.10$)$ \\
\hline Disability based & $1.02(0.86$ to 1.21$)$ & 1.03 (0.97 to 1.10$)$ & 1.14 (1.06 to 1.23$) \ddagger$ & NA§ \\
\hline
\end{tabular}

${ }^{*} \mathrm{P}<0.05$.

$\dagger P=0.06$.

$\ddagger \mathrm{P}<0.001$

$\S$ Disability-based hate crime reports were not available for the 1991-1996 period.

ПP $<0.01$.

BMI, body mass index; CES-D-SF, Centre for Epidemiologic Studies Depression Scale Short Form; CVD, cardiovascular disease ; NA, not available.

higher odds of developing hypertension, respectively. Religion-based hate crime rates were also associated with higher odds of hypertension (OR 1.10;95\% CI 1.01 to 1.20$)$ at the state level.

\section{Depressive symptoms}

The associations between state- or county-level all and race/ethnicity-based hate crime rates and depressive symptoms were in the expected direction. However, they did not reach statistical significance either at the state level (OR $1.03 ; 95 \%$ CI 0.90 to 1.19 ) or county level (OR 1.01; 95\% CI 0.90 to 1.13 ) for all and race/ ethnicity-based hate crimes.

\section{Effect modification}

When we tested for statistical interactions with individual-level race/ethnicity, we observed stronger positive associations between state-level sexual orientation-based hate crimes and diabetes among Whites compared with Blacks ( $\mathrm{p}$ for interaction $=0.02$ ), but not compared with Hispanics/Latinos $(p=0.12)$. We did not find significant interactions between total race/ethnicity-based or race/ethnicity-specific hate crime rates and race/ethnicity. In addition, there were no consistent interactions observed between hate crime rates and sex (data not shown).

\section{DISCUSSION}

In a large, nationally-representative study of middle-aged Americans, we found that higher state-level all hate crime and race/ethnicity-based hate crime rates were associated with higher odds of incident diabetes. Also, at the county level, all hate crime rates predicted higher odds of obesity and race/ethnicity-based hate crime rates predicted higher odds of both hypertension and obesity. As an example comparison, a 1-SD increase in the county-level race/ethnicity-based hate crime rate (2.7 per 100000 population) was associated with a higher odds of developing hypertension comparable to the change associated with approximately 1 year of older age from our same model (OR 1.07; 95\% CI 1.03 to 1.12 for age). No significant associations were observed for depressive symptoms. 
In addition, we did not observe any significant interactions between race/ethnicity-based hate crime rates and individual race/ethnicity.

Our findings are consistent with our priori hypothesis which posited that the presence of bias motivations in crime might represent a potential additional health hazard independent of total crime rates. Moreover, a more consistent pattern was found for crime exposure at the county level compared with the state level. These results are in keeping with Tobler's first law of geography, stating that 'everything is related to everything else, but near things are more related than distant things. ${ }^{, 35}$ In 2010 in the USA, Zhao et al found that the number of crime incidents within a $0.1,0.5$ or 1.0 mile radius of the Houston city residence of 652 respondents was associated with increased fear of crime among the participants. ${ }^{23}$ However, the largest effect estimates were observed for crime incidents within an 0.1 mile radius. ${ }^{23}$ These findings-more proximal exposure to crime leading to a more substantial impact on residents' perception and fear of violence-were later confirmed by Lai et al. ${ }^{24}$ in Houston, Texas, USA ${ }^{24}$ and Sydes $e t a l^{25}$ in Brisbane, Australia. ${ }^{25}$ Fear and psychological stress responses were posited to lead to an increased risk of developing CVD risk factors, which might also partly explain the associations observed in the current study. ${ }^{15}{ }^{17-21}$

Not surprisingly, of all types of hate crimes, race/ ethnicity-based crime rates showed the strongest associations with CVD risk factors. According to the UCR and the National Crime Victimisation Survey (NCVS), between 2000 and 2003, slightly more than half of the hate crime victimisations were due to bias motivations of race/ethnicity $(51.4 \%$ in the UCR, and $56.0 \%$ in the NCVS), making up the majority of all hate crimes. ${ }^{36}$ It was also reported that in 2000-2003, per capita rates of hate crime victimisation did not vary based on the victims' race/ethnicity or sex. For example, neighbourhoods with higher rates of anti-Black crimes might also have higher anti-White crime rates (including eg, retaliatory crimes) affecting both men and women, which might partly explain the mostly non-significant interactions we observed between area-level exposures and race/ ethnicity or sex. ${ }^{36}$

Our study has several strengths. To our knowledge, this is the first work exploring the impact of hate crimes and specific bias motivations as an area-level social determinant on the individual-level health using a nationallyrepresentative sample of middle-aged Americans. Furthermore, we adjusted all models for the county-level and state-level total crime rates, as well as a variety of key potential confounders at the state, county, and individual levels. In addition, we explored our main associations at both the state and county levels, and investigated the possibility of differential effects across subpopulations based on individual race/ethnicity and sex.

Nevertheless, a few limitations should be noted when interpreting our findings. First, racial/ethnic minorities, as opposed to Whites, might be less likely to report to authorities both racial and non-racial hate crimes, which could impede the correct estimation of race/ethnicityspecific associations. ${ }^{37}$ In addition, according to the NCVS, violent crimes were more heavily under-reported at the beginning of the 1990s in the whole population (eg, $50 \%$ of serious violent crimes were unreported in 1994 compared with $42 \%$ in 2010), while around 50\% of hate crime victimisations were not reported between 2000 and 2006. ${ }^{3638} 39$ Therefore, measurement bias might have led to biased effect estimates, also contributing to the null findings on depressive symptoms. Moreover, the CES-D-SF was used to measure depressive symptomatology to screen for actual depression at only two timepoints, with a 10-year gap between measurements. The lack of clinical assessments for diagnoses of depression and the plausibly shorter-term impacts of hate crime rates on mental health could potentially explain the null findings. Second, despite our adjustment for a wide range of covariates, residual or unmeasured confounding (eg, due to income misclassification) might be present and biased our findings. Third, self-reported data were used to measure CVD risk factors. Female participants might report worse or more accurate health status, whereas males tend to under-report chronic health conditions, possibly leading to recall bias. ${ }^{40}{ }^{41}$ Fourth, although we tested a specific hypothesis and our primary exposures were all and race/ethnicity-based hate crime rates, we did assess several bias motivations, which might have led to a multiple comparisons problem, potentially biasing our estimates. However, given the exploratory nature of our study (ie, to examine which group specific bias motivations affect individual health the most), not adjusting for multiple comparisons while still reporting all CIs is consistent with expert recommendations. ${ }^{42}{ }^{43}$ Along with the measurement error mentioned above, this issue could also contribute to the contradicting state-level and countylevel findings on the impacts of sexual orientation-based hate crime rates on diabetes. Nonetheless, the magnitude of the state-level effect estimate was larger than that at the county level (OR 1.23; 95\% CI 1.09 to 1.39 at the state level vs OR $0.91 ; 95 \%$ CI 0.83 to 1.00 at the county level), while the results were consistent across all other bias motivations. Fifth, measuring neighbourhood hate crime rates at a lower aggregation level (eg, census tract level) might be more appropriate to estimate its effects on individuals' health. However, in the NLSY79, we were limited for within-state information on respondents' location of residence to the county and metropolitan statistical area levels. Also, it is crucial to consider the potential spillover effects of crime across neighbourhood boundaries and multiple spatial scales when examining community-level effects. ${ }^{45}$

Finally, due to the lack of information, we could not ascertain whether a respondent was a victim or, potentially, a supporter of hate crimes. In this context, hate crime rates could simultaneously be an exposure (eg, for a member of the target group), and a potential proxy for the prevalence of people who harbour prejudices. For example, in 
a neighbourhood with a high number of White supremacists, the occurrence of anti-Black hate crimes is not an 'exposure' for all White people living in that area. Rather, it is also a proxy measure for the prevalence of anti-Black sentiments in that area. Our study findings appear to suggest that anti-Black hate crimes do not differentially affect Blacks and Whites. It may be the case that while the general outrage in the community could affect the health of all residents, harbouring prejudice and hate might also be unhealthy for the people who hold such views, that is, racism might be toxic to both the victim and the perpetrator. Lastly, anger, hostility, distrust and aggression could also potentially increase CVD risk through adverse health behaviours (eg, drinking, smoking, unhealthy diet) and psychophysiological processes (eg, autonomic dysfunction, inflammation) ${ }^{4-48}$ However, we could not differentiate between the potential health effects of victimisation and the feelings of hate or prejudice.

Further research is needed to estimate the full impact of bias motivations in neighbourhood crime and the mediating pathways through which hate crime rates may affect individual health. These results should be confirmed using longitudinal cohort studies with clinically assessed CVD risk factors linked to neighbourhood-level crime information. Perceptions of neighbourhood crime and feelings of hate and prejudice should be measured and considered in conjunction with reported crime rates to better understand how hate crimes might affect individual health.

\section{CONCLUSIONS}

In summary, this large, nationally-representative study provides novel evidence on the prospective associations between hate crime rates and CVD risk factors among middle-aged USA adults. Our findings suggest that living in areas with higher rates of hate crime, particularly race/ ethnicity-based in nature, may confer higher odds of diabetes, hypertension and obesity, independently of all crime rates. It is critical to understand hate crime as an area-level social determinant as well, affecting the victims, their immediate environment and the entire community. If these findings are confirmed, investing resources into fighting hate crime through increasing public awareness, supporting hate crime reporting, training for effective policing and professional victim assistance and legislative measures reflecting the weight of hate-motivated crimes, as well as education in communities to alleviate extremism and prejudice, may be means to help reduce the national burden of CVD.

\section{Author affiliations}

${ }^{1}$ Department of Health Sciences, Northeastern University Bouve College of Health Sciences, Boston, Massachusetts, USA

${ }^{2}$ Department of Social and Behavioral Sciences, Harvard University T H Chan School of Public Health, Boston, Massachusetts, USA

${ }^{3}$ Department of Economics, Boston College Morrissey College of Arts and Sciences, Chestnut Hill, Massachusetts, USA
${ }^{4}$ Department of Epidemiology, The University of lowa College of Public Health, lowa City, lowa, USA

${ }^{5}$ Department of Pharmacy and Health Systems Sciences, Northeastern University Bouve College of Health Sciences, Boston, Massachusetts, USA

${ }^{6}$ School of Public Policy and Urban Affairs, Northeastern University, Boston, Massachusetts, USA

\section{Twitter Christopher F Baum @kitbaum}

Contributors DK and KG conceived and designed the study. KG analysed the data and wrote the first draft of the manuscript. FN contributed to the study's analytic strategy and the analysis of the data. FN, IK, CFB, RW, BAB and DK helped to interpret the data and critically reviewed the manuscript for important intellectual content. DK obtained funding and supervised the implementation of the study. DK is responsible for the overall content as the guarantor. All authors have seen and approved of the manuscript. The corresponding author attests that all listed authors meet authorship criteria and that no others meeting the criteria have been omitted.

Funding This work was supported by the National Heart, Lung and Blood Institute at the National Institutes of Health (grant R01HL138247; PI: DK).

Competing interests None declared.

Patient and public involvement Patients and/or the public were not involved in the design, or conduct, or reporting, or dissemination plans of this research.

Patient consent for publication Not applicable.

Ethics approval This study was approved by the Institutional Review Board at Northeastern University IRB \# 15-04-16.

Provenance and peer review Not commissioned; externally peer reviewed.

Data availability statement Data are available in a public, open access repository. Data may be obtained from a third party and are not publicly available. Data used in this study were drawn from the National Longitudinal Surveys (https://www.nlsinfo. org/). NLS public-use data for each cohort are available via the NLS Investigator (https://www.nlsinfo.org/investigator/pages/login). NLSY79 confidential restricteduse geocode data are available to US-based researchers upon reasonable request from the Bureau of Labor Statistics (https://www.bls.gov/nls/geocodeapp.htm).

Open access This is an open access article distributed in accordance with the Creative Commons Attribution Non Commercial (CC BY-NC 4.0) license, which permits others to distribute, remix, adapt, build upon this work non-commercially, and license their derivative works on different terms, provided the original work is properly cited, appropriate credit is given, any changes made indicated, and the use is non-commercial. See: http://creativecommons.org/licenses/by-nc/4.0/.

\section{ORCID iDs}

Krisztina Gero http://orcid.org/0000-0002-7596-4125

Christopher F Baum http://orcid.org/0000-0003-4766-3699

\section{REFERENCES}

1 Federal Bureau of Investigation. Hate crimes - FBI. Available: https://www.fbi.gov/investigate/civil-rights/hate-crimes [Accessed 6 Feb 2020].

2 Sullaway M. Psychological perspectives on hate crime laws. Psychology, Public Policy, and Law 2004;10:250-92.

3 Levin B. Hate crimes. J Contemp Crim Justice 1999;15:6-21.

4 Messner SF, Mchugh S, Felson RB. Distinctive characteristics of assaults motivated by bias. Criminology 2004;42:585-618.

5 Ruback RB, Gladfelter AS, Lantz B. Hate crime victimization data in Pennsylvania: a useful complement to the uniform crime reports. Violence Vict 2018;33:330-50.

6 Pezzella FS, Fetzer MD. The likelihood of injury among bias crimes: an analysis of general and specific bias types. $J$ Interpers Violence 2017;32:703-29.

7 Federal Bureau of Investigation. Federal Bureau of investigation crime data explorer, 2021. Available: https://crime-data-explorer.fr. cloud.gov/pages/explorer/crime/hate-crime [Accessed 12 Nov 2021].

8 Gover AR, Harper SB, Langton L. Anti-Asian Hate crime during the COVID-19 pandemic: exploring the reproduction of inequality. Am J Crim Just 2020;45:647-67.

9 Iganski P. Hate crimes hurt more. Am Behav Sci 2001;45:626-38.

10 Perry B, Alvi S. 'We are all vulnerable': The in terrorem effects of hate crimes. Int Rev Vict 2012;18:57-71.

11 Lannert BK. Traumatogenic processes and pathways to mental health outcomes for sexual minorities exposed to bias crime information. Trauma Violence Abuse 2015;16:291-8. 
12 Bor J, Venkataramani AS, Williams DR, et al. Police killings and their spillover effects on the mental health of black Americans: a population-based, quasi-experimental study. Lancet 2018;392:302-10.

13 Das A, Singh P, Kulkarni AK, et al. Emergency department visits for depression following police killings of unarmed African Americans. Soc Sci Med 2021;269:113561.

14 Craig KM. Retaliation, fear, or rage: an investigation of African American and white reactions to racist hate crimes. $J$ Interpers Violence 1999;14:138-51.

15 Hill TD, Ross CE, Angel RJ. Neighborhood disorder, psychophysiological distress, and health. J Health Soc Behav 2005;46:170-86.

16 Tafet GE, Nemeroff CB. The links between stress and depression: psychoneuroendocrinological, genetic, and environmental interactions. J Neuropsychiatry Clin Neurosci 2016;28:77-88.

17 Elliott M. The stress process in neighborhood context. Health Place 2000;6:287-99.

18 Augustin T, Glass TA, James BD, et al. Neighborhood psychosocial hazards and cardiovascular disease: the Baltimore memory study. Am J Public Health 2008;98:1664-70.

19 Chum A, O'Campo P, O’Campo P. Cross-sectional associations between residential environmental exposures and cardiovascular diseases. BMC Public Health 2015;15:438.

20 Tung EL, Chua RFM, Besser SA, et al. Association of rising violent crime with blood pressure and cardiovascular risk: longitudinal evidence from Chicago, 2014-2016. Am J Hypertens 2019;32:1192-8.

21 Tung EL, Wroblewski KE, Boyd K, et al. Police-recorded crime and disparities in obesity and blood pressure status in Chicago. J Am Heart Assoc 2018;7:e008030.

22 Churchwell K, Elkind MSV, Benjamin RM, et al. Call to action: structural racism as a fundamental driver of health disparities: a presidential Advisory from the American heart association. Circulation 2020;142:E454-68.

23 Zhao JS, Lawton B, Longmire D. An examination of the Micro-Level Crime-Fear of crime link. Crime \& Delinquency 2015;61:10.1177/0011128710386203:19-44.

24 Lai Y-L, Zhao JS, Longmire DR. Specific crime-fear linkage: the effect of actual burglary incidents reported to the police on residents fear of burglary. J Crime Justice 2012;35:13-34.

25 Sydes M, Wickes R, Zahnow R. Distance to crime : How proximity shapes residents' perceptions of neighbourhood violence. In: Wickes R, Mazerolle L, eds. Crime and disorder in community context. New York, NY: Routledge, 2021: 63-81.

26 Levine SZ. Evaluating the seven-item center for epidemiologic studies depression scale short-form: a longitudinal U.S. community study. Soc Psychiatry Psychiatr Epidemiol 2013;48:10.1007/s00127012-0650-2:1519-26.

27 Federal Bureau of Investigation. Uniform crime reporting (UCR) program - FBI. Available: https://www.fbi.gov/services/cjis/ucr [Accessed 7 Feb 2020].

28 Kaplan J. Jacob Kaplan's Concatenated Files: Uniform Crime Reporting (UCR) Program Data: Hate Crime Data 1991-2017. Ann Arbor, MI: Inter-university Consortium for Political and Social Research, 2019.
29 Braubach M, Fairburn J. Social inequities in environmental risks associated with housing and residential location--a review of evidence. Eur J Public Health 2010;20:36-42.

30 Suglia SF, Shelton RC, Hsiao A, et al. Why the neighborhood social environment is critical in obesity prevention. J Urban Health 2016;93:206-12.

31 U.S. Census Bureau. American FactFinder, 2019. Available: https:// factfinder.census.gov/faces/nav/jsf/pages/index.xhtml [Accessed 5 Nov 2019].

32 US Census Bureau. State and County Intercensal datasets: 19902000, 2017. Available: https://www.census.gov/data/datasets/ time-series/demo/popest/intercensal-1990-2000-state-and-countycharacteristics.html [Accessed 7 Feb 2020].

33 US Census Bureau. USA counties: 2011, 2019. Available: https:// www.census.gov/library/publications/2011/compendia/usa-counties2011.html\#POP [Accessed 7 Feb 2020].

34 Hair JF, Black WC, Babin BJ. Multivariate data analysis: a global perspective. 7th ed. London, Upper Saddle River, NJ: Pearson, 2010.

35 Tobler WR. A computer movie simulating urban growth in the Detroit region. Econ Geogr 1970;46:240.

36 Caroline WHB, Statistician B. Hate crime reported by victims and police, 2005. Available: https://www.bjs.gov/content/pub/pdf/hcrvp. pdf [Accessed 21 Dec 2020].

37 Zaykowski H. Racial disparities in hate crime reporting. Violence Vict 2010;25:378-94.

38 Langton L, Berzofsky M, Krebs C. Victimizations not reported to the police, 2006-2010, 2012. Available: https://www.bjs.gov/content/ pub/pdf/vnrp0610.pdf [Accessed 21 Dec 2020].

39 Sandholtz N, Intern B, Langton L. Hate crime victimization, 20032011, 2013

40 Rothman KJ, Greenland S, Lash TL. Modern epidemiology. 3rd ed. Philadelphia, PA: Lippincott Williams \& Wilkins, 2008.

41 Merrill SS, Seeman TE, Kasl SV, et al. Gender differences in the comparison of self-reported disability and performance measures. $J$ Gerontol A Biol Sci Med Sci 1997;52:M19-26.

42 Althouse AD. Adjust for multiple comparisons? It's not that simple. Ann Thorac Surg 2016;101:1644-5.

43 Rothman KJ. Six persistent research misconceptions. J Gen Intern Med 2014;29:1060-4.

44 Zhang $\mathrm{H}$, Song W. Addressing issues of spatial spillover effects and non-stationarity in analysis of residential burglary crime. GeoJournal 2014;79:89-102.

45 Mair C, Sumetsky N, Gaidus A, et al. Multiresolution analyses of neighborhood correlates of crime: smaller is not better. $A m \mathrm{~J}$ Epidemiol 2021;190:150-60.

46 Everson-Rose SA, Lewis TT. Psychosocial factors and cardiovascular diseases. Annu Rev Public Health 2005;26:469-500.

47 Hostility AS. Anger, and cardiovascular mortality among blacks and whites. Res Cardiovasc Med 2017;6:e34029.

48 Smaardijk VR, Lodder P, Kop WJ, et al. Sex- and genderstratified risks of psychological factors for incident ischemic heart disease: systematic review and meta-analysis. J Am Heart Assoc 2019;8:e010859. 